\title{
VISITE DES ÉVÊQUES FRANÇAIS EN POLOGNE EN 1924 À LA LUMIÈRE DE DOSSIER DÉPOSÉ PAR LE CARDINAL DUBOIS DANS LES ARCHIVES HISTORIQUES DU DIOCĖSE DE PARIS
}

\begin{abstract}
Résumé
À la fin 1923, plus de 100000 Polonais étaient arrivés en France . Ce sont les aux agriculteurs de Galiceet les mineurs polonais de Westphalie et de la Rhénanie. Les Polonais considéraient leur séjour en France comme temporaire. Il est naturel que, attachés à la religion catholique enrichie de rites indigènes, ils demandent la pastorale des prêtres polonais. Le plus grand problème pour mener une pastorale polonaise en France c'était l'attitude du clergé français, qui s'est méfié des coutumes religieuses polonaises. Pour le primat de Pologne, la meilleure façon de familiariser les évêques français avec les spécificités de la pastorale polonaise était de les inviter à visiter la Pologne. Cette visite a eu lieu du 14 au 28 juin 1924.

À Paris (archives historiques du diocèse de Paris) est conservé le dossier concernant la visite des évêques français en Pologne en 1924. La lecture des documents permet de connaitre les réactions des invités français pendant et après le voyage en Pologne.
\end{abstract}

Mots-clés: Dubois; Dalbor; Chaptal; Baudrillart; France; émigration

Les débuts de l'émigration économique polonaise vers la France remontent à 1907, lorsque les premiers ouvriers agricoles sont venus de Galice en Lorraine. La possibilité de gagner deux fois plus qu'en Pologne fait qu'en 1910, il y a presque six mille ouvriers agricoles en France et à la veille du déclenchement de la Première Guerre mondiale il y en a plus de dix mille1. Dans le même temps, les premiers groupes de mineurs polonais de la Rhénanie sont venus en France 2 .

* Ks. Michał Kłakus - dr historii Kościoła; e-mail: mklakus@gmail.com

https://orcid.org/0000-0002-0012-7525

${ }^{1} \mathrm{~J}$. Ponty, Polonais méconnus. Histoire des travailleurs immigrés en France dans l'entre-deuxguerres, Paris 2005, p. 15; R. Dzwonkowski, Polska opieka religijna we Francji 1909-1939, Poznań-Warszawa 1988, p. 25.

${ }^{2}$ En 1910, 130000 mineurs polonais travaillaient dans le bassin rhéno-westphalien. En additionnant hommes, femmes et enfants ils seraient presque 500000 personnes. Ponty, Polonais méconnus, p. 24. 
Contrairement aux agriculteurs de Galice, leur désir de venir en France était motivé par le souci de préserver la tradition nationale polonaise, ce qui était difficile en raison de la politique répressive menée en Prusse. De plus, les mineurs de Westphalie, installés en France, ont cultivé dans ce pays une riche vie culturelle et religieuse, exprimée par de nombreuses associations polonaises, des confréries et des associations sportives, culturelles, patriotiques et religieuses ${ }^{3}$. Déjà en 1910 existent à Barlin (Pas-de-Calais) la première association de Sainte Barbe, et à Lallaing (Nord) celle de Saint Adalbert ${ }^{4}$. En 1912, 620 mineurs polonais travaillaient déjà dans les départements où l'industrie houillère était la plus développée (Nord et Pas-de-Calais) ${ }^{5}$.

Cependant, la plus grande vague de travailleurs polonais est arrivée en France après la fin de la Première Guerre mondiale. Elle a été causée par une pénurie importante sur le marché du travail français à la suite du décès pendant la guerre de près de $17 \%$ des hommes âgés de 18 à 60 ans $^{6}$, ainsi que par le manque d'offres d'emploi pour les mineurs polonais de Westphalie et de la Rhénanie dans l'État polonais en plein essor.

À la fin 1923, plus de 100000 Polonais étaient arrivés en France et leur nombre augmentait rapidement ${ }^{7}$. Ils se sont installés principalement dans les départements du Nord et du Pas-de-Calais. Pour les ouvriers polonais, les autorités minières ont organisé des colonies nationales. Les Polonais considéraient leur séjour en France comme temporaire, ils n'étaient donc pas intéressés à apprendre le français. Les activités des associations établies parmi les Polonais étaient également orientées vers la protection de la langue maternelle et la préservation des traditions et coutumes polonaises. Ces éléments ont donc empêché l'assimilation de la population des immigrés avec la population locale. Il est naturel que, attachés à la religion catholique enrichie de rites indigènes, ils demandent la pastorale des prêtres polonais.

Cependant, la convention signée le 3 septembre 1919 sur la méthode de recrutement des Polonais pour travailler en France ne garantit pas la fourniture d'une protection religieuse aux Polonais. C'est le clergé polonais qui, présente à Paris depuis 1836 (Mission Catholique Polonaise, existe formellement depuis

${ }^{3}$ J. Kozłowski, Tradycje westfalskie wśród wychodźstwa polskiego we Francji, „Przegląd Polonijny”, 1 (1993) p. 55-67; R. Dzwonkowski, Geneza i rola przywódczej grupy społecznej w historii polskiej emigracji zarobkowej we Francji, 1920-1945, „Przegląd Polonijny”, 3 (1979) p. 69-82; J. Michel, L'identité religieuse et nationale des mineurs polonais dans le Nord de la France et dans la Ruhr: etude comparée, w: Les contacts religieux franco-polonais du moyen age à nos jours relations, influences, images d'un pays vu pas l'autre, Paris 1985, p. 589-596.

${ }^{4}$ G. Garçon, Les catholiques polonais en France 1919-1949, Lille 2004, p. 25.

${ }^{5}$ Ponty, Polonais méconnus, p. 26.

${ }^{6}$ H. Chałupczak, E. Kołodziej, Zjazdy i konferencje Konsulów Polskich we Francji. Protokoły i referaty 1931-1938, Lublin 2009, p. 13.

${ }^{7}$ En mars 1921, selon les résultats des recensements, la France abritait 45766 Polonais. En 1926 ils ont été 309000 personnes. Dans le Pas-de Calais 3371 Polonais (1921) et 91000 (en 1926). Ponty, Polonais méconnus, p. 118. 
$1922^{8}$ ), était responsable de l'organisation des activités pastorales pour les Polonais. Cependant, en raison de l'afflux massif d'émigrés économiques polonais vers la France après la fin de la Première Guerre mondiale, il n'y avait pas de règlement déterminant la manière d'organiser ce ministère dans les colonies ouvrières polonaises ni parmi les agriculteurs polonais employés dans les fermes françaises. Le Primat de Pologne Edmund Dalbor a été informé par les prêtres Stanisław Adamski (1919) et Arkadiusz Lisiecki (1921) de la situation tragique de la Mission Catholique Polonaise en France ${ }^{9}$. En conséquence il a décidé de réorganiser ses activités. En mai 1922 il a nommé le nouveau recteur à Paris. Leon Postawka (prêtre malade, presque aveugle, âgé de 84 ans) a été remplacé par Wilhelm Szymbor (Lazariste, prêtre expérimenté qui a bien connu la réalité de vie des émigrés). Dès les premiers jours, il a commencé à réorganiser les structures de la Mission en France.

Le 19 juin 1922, le Cardinal polonais Edmund Dalbor et Monseigneur Emmanuel Chaptal - l'évêque responsable de la pastorale des étrangers dans le diocèse de Paris - ont approuvé les nouveaux statuts de la Mission Catholique Polonaise à Paris. C'était possible grâce à la bienveillance de Msg. Chaptal envers les missions catholiques étrangères existant à Paris (italien, allemand, néerlandais, hongrois, luxembourgeois, suédois, tchèque et slovaque). Lui-même a participé souvent aux fêtes organisées par des immigrés à Paris. Pour les célébrations dans les langues étrangères il a prêté l'église jésuite (rue de Sèvres). C'est grâce à lui que de nouvelles missions, telles que russe, ukrainienne, arménienne ou syrienne, ont été fondées à Paris. Cependant, il faut ajouter que pour Msg Chaptal ses activités parmi les immigrés à Paris n'étaient pas désintéressées, car elles lui permettaient de contrôler les activités des missionnaires étrangers ${ }^{10}$.

Un autre objectif du Primat de Pologne (Dalbor) était d'élaborer un document dans lequel seraient précisées les règles concernant l'organisation de la pastorale pour l'émigration polonaise. En plus le Cardinal Dalbor a voulu préparer les règles non pas seulement pour les Polonais qui vivent dans la région parisienne mais pour toute la France. Le plus grand problème pour mener une pastorale polonaise en France c'était l'attitude du clergé français, qui s'est méfié des coutumes religieuses polonaises. Cette attitude est due à l'ignorance de la culture slave et de la tradition nationale de l'émigration polonaise ${ }^{11}$. Pour le primat de Pologne, la meilleure façon de familiariser les évêques français avec les spécificités de la

${ }^{8}$ M. Brudzisz, Stan badań nad dziejami Polskiej misji Katolickiej we Francji, w: S. Zych, B. Walicki, W kręgu badań nad Polonia i duszpasterstwem polonijnym. Istota i metodologia, Lublin-Sokołów Małopolski 2015, p. 326-328.

${ }^{9}$ C'est aussi prêtres polonais Leon Kalinowski et Teodor Taczak ont présenté au Primat de Pologne des propositions pour l'organisation de la pastorale polonaise en France, voir: M. Brudzisz, Pierwsze zebranie księży Polskiej Misji Katolickiej we Francji, „Studia Polonijne”, 33 (2012), p. 143.

${ }^{10}$ P. Boisard, Monseigneur Chaptal. Evêque d'Isionda (1861-1943), Paris 1945, p. 46-47; R. Schor, L'opinion francaise et les étrangers en France 1919-1939, Paris 1985, p. 333.

${ }^{11}$ J. Szymański, ,Nie chcemy tego ukrywać” - oczami świadków. Sytuacja duszpasterstwa polonijnego w pótnocnej Francji w 1928 roku, „Archiwa, Biblioteki i Muzea Kościelne”, 98 (2012) p. 407-417. 
pastorale polonaise était de les inviter à visiter la Pologne. Les évêques polonais lors d'une réunion à Varsovie (9-10 février 1923) ont accepté avec enthousiasme cette idée (organiser le séjour des évêques français en Pologne). Dès le 16 février 1923, le primat de Pologne a demandé au recteur de la Mission Catholique Polonaise à Paris de sonder l'archevêché de Paris afin de savoir si les autorités ecclésiastiques françaises acceptaient de venir en Pologne du 2 au 15 juin 1923. Le Primat de Pologne a proposé la visite de Poznań, Gniezno, Varsovie, Lublin, Częstochowa et Katowice. Il a aussi demandé qui parmi les évêques français serait intéressé de passer quelques jours en Pologne? ${ }^{12}$

Finalement cette visite a eu lieu un an plus tard. Elle a duré du 14 au 28 juin 1924. Les évêques français ont visité les grandes villes polonaises: Poznan, Gniezno, Varsovie, Czestochowa et Katowice (peut-être en raison de manques de temps ils n'ont pas pu visiter Lublin ${ }^{13}$ ). Ces villes n'étaient pas choisies par hasard. C'était les lieux historiques et spirituels les plus importants de Pologne mais aussi les capitales des régions d'où provenaient en grande partie les émigrants polonais en France. En Pologne sont arrivés: le Cardinal Louis Dubois - Archevêque Paris (1856-1929) - mais aussi Monseigneur Alfred Baudrillart - Recteur de l'Institut catholique à Paris (1859-1942) - Monseigneur John Arthur Chollet - Archevêque de Cambrai (1862-1952) - Monseigneur Eugène Louis Julien - Evêque d'Arras (1856 - 1930) - Monseigneur Emmanuel Chaptal (1861-1943), Monseigneur Charles Marie Delabar - Vicaire général du diocèse de Paris (1867-1937) - et le père Wilhelm Szymbor (1879-1949). Comme on l'a déjà mentionné, l'objectif principal de la visite était de préparer un Règlement qui fixerait le statut des pasteurs polonais en France et établirait la manière d'organiser la pastorale des émigrants polonais en France. Ainsi, les autorités religieuses polonaises ont voulu montrer aux invités français la richesse et l'indissolubilité de la tradition nationale et religieuse polonaise.

Non seulement l'Église, mais aussi l'État et les responsables des entreprises privées en Pologne se sont joints pour préparer cette visite. Les évêques français ont été accueillis avec un grand enthousiasme en Pologne. Aux réunions avec les représentants de l'Église en France ont assisté non seulement les évêques polonais mais aussi les autorités étatiques et locales, les délégations militaires, les représentants de l'aristocratie, le monde de la science et de la culture, les présidents des associations religieuses ainsi que les représentants de la mission diplomatique française accrédités en Pologne. Partout les hôtes français ont été suivis par des foules de fidèles. Les évêques français ont été très impressionnés par le développement de la vie religieuse dans la deuxième République polonaise. Le résultat direct de la visite fut la signature en janvier 1925 d'un accord sur l'organisation de la pastorale polonaise en France.

De sources françaises, le déroulement de la visite des évêques français est principalement connu par des récits publiés de ce voyage par cardinal Baudril-

${ }^{12}$ Archives historiques $d u$ diocèse de Paris, Louis-Ernest Dubois (sygn. 1D 12,23) [AHP], Dalbor à Szymbora, Poznań 16 II 1923.

${ }^{13} 20$ VI 1924 cardinal Baudrillart est parti à Lublin seul. Les autres sont restés à Varsovie. 
lart $^{14}$. Ils ont été utilisés dans les publications préparées par Y. Marchasson ${ }^{15}$, M. Trąba ${ }^{16}$, M. Satora ${ }^{17}$.

R. Dzwonkowski, décrivant le voyage susmentionné ${ }^{18}$ a également fait référence à des documents trouvés aux archive des archevêchés de Cracovie. Il a mentionné - mais sans les utiliser (page 233 de son livre) - des documents existants sur ce sujet dans les archives historiques de l'archidiocèse de Paris. La visite a été largement relatée dans l'hebdomadaire «Polak we Francji (Polonais en France)» publié à Paris depuis le mois décembre 1923.

À Paris est conservé le dossier concernant la visite des évêques français en Pologne en 1924. Il y a été déposé par le Cardinal Dubois. Dans ce dossier, on trouve:

- des documents confidentiels établis par les autorités ecclésiastiques en Pologne et en France (correspondance concernant la préparation de la visite, rapports sur son déroulement, y compris une lettre du Cardinal Dubois adressée au pape Pie XI, dans laquelle l'archevêque de Paris partage ses impressions de la visite, présente des suggestions et propositions),

- des documents officiels ainsi que les programmes détaillés des visites ${ }^{19}$ (p.ex.: le temps de voyage entre les étapes successives ${ }^{20}$ ), les événements culturels préparés spécialement pour les invités français, les discours prononcés pendant le séjour des dignitaires français en Pologne, les rapports (préparées en polonais et en français) des activités d'associations religieuses existant non seulement en Pologne, mais aussi en France.

Le Cardinal Dubois a gardé dans son dossier les coupures des journaux polonais où l'on décrivait avec enthousiasme le témoignage solennel de l'amitié mutuelle entre les deux pays. On trouve des extraits de la presse catholique: du «Przewodnika Katolickiego $»^{21}$, clérical et antisémite «Głos Narodu» $»^{22}$, natio-

${ }^{14}$ A. Baudrillart, Les évêques français en Pologne, Paris 1925; P. Christopne (red.), Les carnets $d u$ cardinal Alfred Baudrillart (1922-25), Paris 2001, et les relations publiee dans les „Amitiés catholiques françaises" en 1924.

${ }^{15}$ Y. Marchasson, Monseigneur Beaudrillart et la Pologne (1919-1939), w : Les Contacts religieux franco-polonais du Moyen Age à nos jours. Relations, influences, images d'un pays vu par l'autre, Paris 1985.

${ }^{16}$ M. Trąba, Relacja biskupa Alfreda Baudrillarta z pobytu na polskim Górnym Śląsku w 1924 roku, „Zeszyty Chorzowskie”, 8 (2005) p. 62-95.

${ }^{17}$ M. Satora, Obraz Polski w dziennikach cardinalynała Alfreda Baudrillarta, ,Dzieje Najnowsze", 2b (2015) p. 21-32.

${ }^{18}$ R. Dzwonkowski, Polska opieka religijna we Francji 1909-1939, Poznań-Warszawa 1988, p. 75-77.

${ }^{19}$ AHP, Programme du sejour de NN.S.S les Evêques francais a Poznan ; Ibid., Programme a Katovice ; Ibid., Programme de la réception a Varsovie ; Ibid., Programme de la Réception des eveques français a Cracovie.

${ }^{20}$ Par exemple le voyage dePoznan à Gniezno durait $1 h 15$, Ibid., Programme du sejour de NN.S.S les Evêques francais a Poznan.

${ }^{21}$ b.a., Witajcie w Polsce, Najdostojniejsi Książęta Kościoła francuskiego, „Przewodnik Katolicki" z 22 VI 1924, p. 1.

${ }^{22}$ b.a., Les Evêques de France en Pologne, „Głos Narodu” z 16 VI 1924, p. 1. 
nal-démocratie «Gazeta Warszawska» ${ }^{23}$, «Goniec Częstochowski»» ${ }^{24}$, «Kurier Poznański» ${ }^{25}$, des chrétiens-démocrates „Gońca Śląskiego ${ }^{26}$, et même socialiste „Naprzód” ${ }^{27}$. Les descriptions du voyage des évêques français en Pologne ont été préparées par Robert Vaucher ${ }^{28}$ et publiées en français à Varsovie dans «Le Journal de Pologne $\rangle^{29}$. En particulier, la présence de l'organe officiel du parti socialiste en Pologne («Naprzód») parmi les coupures de presse présentées aux invités français leur montre que leur visite a été suivie non seulement par les «collaborateurs et amis de l'Église» mais aussi par tous les milieux politiques en Pologne. En parcourant les documents conservés à Paris, nous trouvons également des cartes de menu ou les cartes de visite.

Le Cardinal Dubois a informé du projet de ce voyage le Pape Pie XI (nous n'oublions pas qu'Achille Ratti était le premier nonce à Varsovie après 1918) était parfaitement conscient de la situation sociopolitique en Pologne. Il a donc soutenu cette visite et il a donné sa bénédiction aux participants. Le choix de la délégation n'était pas accidentel. Il a été fait personnellement ${ }^{30}$ par le cardinal Dubois, qui a invité à participer à l'expédition les évêques des deux diocèses français où la colonie polonaise était la plus importante (Cholet de Cambrai et Julien d'Arras), «l'évêque des étrangers» à Paris (Chaptal), «l'ami des Polonais» et fondateur des amitiés catholiques françaises (Baudrillart). En outre, comme on l'a déjà mentionné ils ont été accompagnés par le vicaire général de Paris (Delabar) et le recteur de la Mission catholique polonaise (Szymbor), qui a été leur traducteur.

Le 11 juin 1924, les évêques français quittaient la France pour la Suisse. En passant par le col d'Arlberg, ils atteignirent Vienne, où l'archevêque de Vienne, le cardinal Friedrich Gustaw Piffl, les attendait avec le Chancelier d'Autriche, le Père Ignaz Seipel. Le matin du 14 juin 1924, ils sont arrivés au poste-frontière avec la Pologne (Dziedzice) . Le clergé polonais, les autorités civiles et militaires et le consul de France leur avaient préparé un accueil enthousiaste. Pendant la visite - selon la relation du cardinal Dubois - les dignitaires français ont entendu souvent l'hymne de la «Marseillaise». Les discours prononcés en français ont exprimé leur gratitude d'être venus. Celle-ci était assurée d'une amitié réciproque et permanente entre les deux pays avec une seule âme» ${ }^{31}$. À Varsovie, les invités français ont pu entendre lors d'un discours en français au nom de l'organisation nationale des femmes polonaises que «la France catholique est un exemple vers laquelle nous fixons nos yeux et avec un désir ardent de pouvoir atteindre son niveau» et que «l'amitié franco - polonaise est une tradition nationale en Po-

${ }^{23}$ b.a., Francuscy dostojnicy kościelni w Poznaniu, „Gazeta Warszawska” z 22 VI 1924, p. 1.

${ }^{24}$ b.a., Przyjazd Episkopatu francuskiego do Częstochowy, „Goniec Częstochowski” z 17 VI 1924, p. 1.

${ }^{25}$ b.a., Biskupi francuscy w Poznaniu, „Kurier Poznański” z 24 VI 1924, p. 2

${ }^{26}$ b.a., Biskupi francuscy w Katowicach, „Goniec Śląski” z 28-29 VI 1924, p. 2

${ }^{27}$ b.a., Wycieczka biskupów francuskich w Krakowie, „Naprzód” z 16 VI 1924, p. 6.

${ }^{28}$ Le correspondant du journal « Petit Parisien »

${ }^{29}$ Delagneau F., Les évêques francais en Pologne, „Le Journal de Pologne” z 17 VI 1924, p. 1.

${ }^{30}$ AHP., Dubois do Piusa XI , Paryż b.d.

${ }^{31}$ Ibid, Compte - rendu du visite. Mission en Pologne, Paris, b.d. 
logne $»^{32}$. Le 23 juin 1924, à Gniezno, le professeur Rudolf Nowowiejski, dans un discours sous forme de poème en l'honneur des distingués invités, a rappelé l'amitié qui relie les deux nations et a fait l'éloge de la terre française ${ }^{33}$. Il a dit:

Vénérés Prélats de France - Soyez chez nous bienvenus ! - Notre foi, notre espérance - Ont nos peuples soutenus- Le séjour sur notre terre - Est un gage précieux - de l'amitié séculaire - qui nous unit tous les deux. (...) Gloire à la française terre! Honneur à la papauté ! Tout l'enfer dans sa colère - De Dieu cerne la Cité - Entends la voie redoutable - serpent, tu dois succomber - A jamais inébranlable - Reste Pierre, le rocher!

À Katowice, un mineur a rappelé dans un discours que

Nous sommes tout particulièrement touchés de voir réunis autour de Votre Éminence tant d'évêques mineurs, protecteurs de notre profession: Mgr. Cholet, Mgr Julien, Mgr Hlond.(....) J'ai vu, Éminence, il $\mathrm{y}$ a tout juste quatre années et la Haute Silésie n'était alors polonaise que de cœur, j'ai vu la Pologne en formation, pauvre a-t-on dit, d'expérience, mais pauvre surtout de moyens matériels, riche seulement de l'amour de la patrie et de la volonté de la faire grand (...). Certes, l'avenir est encore lourd de difficultés, mais le souvenir du passé nous réconforte, avec l'aide de la Providence que nous implorons et de la bénédiction que vous nous avez apportée; nous avons confiance ${ }^{34}$.

Les évêques français ont été impressionnés par les églises remplies, les dizaines de milliers de participants, et surtout par les enfants participant aux cérémonies en l'honneur des invités de France, mais aussi par l'implication des autorités laïques dans leur organisation ${ }^{35}$. Le Cardinal Dubois, en décrivant la procession de la «Fête Dieu» à Varsovie (19 juin 1924), a écrit:

messe et procession splendides, officiels en présence du Président de la République, du Cardinal, des ministres, des diplomates, des Facultés (en robe) et des soldats en tenue (...) Le Cardinal est escorté par le Président de la République et le Président du Conseil. (...) Le Président a suivi à pied.

En Haute Silésie, qui était un grand chantier de construction, où les évêques français ont passé trois jours, ils ont été impressionnés par le fait que les ouvriers polonais n'avaient pas succombé à l'agitation communiste mais étaient restés fidèles à l'Eglise. Pour le Cardinal Dubois (comme il a écrit au pape Pie XI) c'était grâce à l'action pastorale menée par l'administrateur apostolique August Hlond.

Comme déjà mentionné, la visite des dignitaires français s'est accompagnée de performances artistiques. Par exemple, le 16 juin 1924, ils ont participé à un concert matinal à Cracovie, tandis que le 26 juin 1924 à Katowice, ils ont écouté un programme préparé par l'orchestre militaire du 73e Régiment d'infanterie

${ }^{32}$ Ibid., Eminance, Messeigneurs...., Varsovie b.d.

${ }^{33}$ Ibid., Nowowiejski R., Aux évêques de France a Gniezno, Gniezno 23 VI 1924.

${ }^{34}$ Ibid., Szcześć Boże! Bonheur en Dieu, Katowice, b.d.

${ }^{35}$ Zwłaszcza że we Francji od 1905 r. nastąpił rozdział Kościoła i państwa, a tym samym Kościół przestał spełniać funkcje publiczne, a Republika stała się w zupełności laicka. 
sous la direction de Maksymilian Chmielewicz et le chœur d'hommes «Echo». Le programme des concerts comprenait des parties du répertoire national (chansons nationales-patriotiques, fragments d'œuvres de Moniuszko, Osomański ou Chlondowski) et international (œuvres de Puccini ou du compositeur austro-hongrois Franz Doppler) ${ }^{36}$.

Par curiosité, on peut dire que lors des repas ${ }^{37}$ la cuisine polonaise était préférée (bouillon, soupe de légumes, bortsch, homards roulés en polonais, tartes, asperges polonaises, poulet rôti, dinde, cerf rôti, sandre, truite, brochet), mais des plats traditionnels français de la région Rhône-Alpes (truite au bleu), ou témoignant de l'amitié franco-polonaise, qui remonte à l'époque de la reine Maria Leszczyńska («baba au rhum») ont également été appréciés. La compote était servie comme boisson, mais aussi des vins hongrois (Tokay), rhénans, français (Bordeaux, Médoc, Champagne) ainsi que du cognac, des liqueurs et de la vodka.

Le vendredi 29 juin 1923 à 5 h30 les évêques rentraient en France via Vienne où ils ont été reçus par le ministre français. Le Cardinal Dubois, dans son rapport après son retour en France, a écrit qu'à Cracovie les évêques français étaient ravis de la richesse de la culture polonaise, que cette ville, capitale intellectuelle, était le berceau de la nationalité polonaise. Ils ont perçu Varsovie comme une ville moderne et ont caractérisé Poznan comme foyer de la vie nationale d'autant plus ardent qu'elle était plus opprimée. Pour eux la Haute Silésie était un centre industriel profondément catholique et Czestochowa était le sanctuaire national ${ }^{38}$.

Comme déjà mentionné, pour les évêques polonais le but principal de cette visite était de préparer les règles de la pastorale polonaise parmi les émigrés en France. Ainsi, lors de leur visite en Pologne, les évêques français ont eu l'occasion de découvrir la richesse des formes d'implication des fidèles dans la vie de l'Église. Spécialement pour eux, les responsables des mouvements et associations religieuses ont préparé (en français) des rapports contenant l'histoire des organisations et leurs programmes qu'ils ont ensuite présentés lors des messes, des académies et des réunions en l'honneur des invités étrangers ${ }^{39}$.

Par exemple, les évêques français ont pu découvrir que grâce aux actions de charité menées par l'Association de Saint Vincent dans les paroisses de Varsovie et Czerników, Pruszków, Lublin, Siedlce, Płock et Grodno, on avait distribué

${ }^{36}$ AHP, Program koncertu na raucie w dniu 26 VI 1924.

${ }^{37} 17$ VI 1924 les évêques français ont diné chez comte Adam Zamoyski. Le jour suivant ils ont diné chez cardinal Kakowski à Varsovie. 19 VI 1924 ils ont déjeuné chez Mons. Gal et le soir chez le Président de la République. 26 VI 1924 ils ont déjeuné chez Ms et Mme Korfanty à Katowice.

${ }^{38}$ Ibid., Compte - rendu du visite. But du voyage, Paris, b.d.

${ }^{39}$ Ibid., Sommaire des oeuvres principal es de l'Association catholique des femmes polonaises, Ibid., Statut de l'association des amis de la musique gregorienne a Varsovie ; Ibid., La Congregation mariale des etudiantes de Varsovie ; Ibid., La Societe des Amis de la musique liturgique a Varsovie ; Ibid., Sommaire de la Société des Dames de la Charité de Saint Vincent de Paul, Ibid., La congrégation des enfants de Marie, Ibid., Union des associations polonaise, l'association des adorateurs du sacre coeur de Jesus ; Ibid., Union de Cercles de Propriétés rurales et fermières «Ziemianki »; Ibid., Union centrale des Associations de la jeunesse Polonaise à Poznan ; Ibid., Mission catholique des Gares de Poznan. 
$92916 \mathrm{~kg}$ de nourriture, on avait effectué 12134 visites des familles et que les frais de gestion s'élevaient à 1779250379 marks polonais ${ }^{40}$. Les membres de l'association catholique d'aide aux jeunes filles ont distribué à Varsovie (église de Sainte Anne) 900 repas par jour ${ }^{41}$.

Les évêques ont pu s'informer sur les activités des institutions sociales laïques opérant parmi les mineurs, comme la société Bracka à Tarnowskie Góry. Ils ont également reçu les statuts des associations polonaises en France ${ }^{42}$ et le programme d'une campagne caritative menée par Jadwiga Zamoyska ${ }^{43}$.

Les évêques polonais ont voulu établir une coopération entre les libraires catholiques polonais et français pour distribuer des livres français religieux en Pologne ; en particulier pour que la librairie de Saint Audibert à Poznań puisse payer après réception des livres en français ${ }^{44}$.

Cependant, selon des documents recueillis dans les archives à Paris, l'objectif principal de la visite pour la délégation française était de renforcer les liens mutuels entre les deux nations ${ }^{45}$. Comme l'a écrit le Cardinal Dubois ils ont vu la Pologne fortement attachée à la France, une Pologne qui a compté (et qui compte) toujours sur l'aide de la France. Ils ont vu des Polonais profondément liés à l'Église catholique et imprégnés d'une foi vivante, simple, pratique et enthousiaste. Ils ont découvert une nation profondément religieuse avec un fort culte marial, comptant sur la providence divine dans les moments difficiles ${ }^{46}$. Pour le Cardinal Dubois, le danger pour le développement de la nation polonaise et la préservation des traditions religieuses polonaises était: l'idéologie du bolchevisme ${ }^{47}$. Selon le Cardinal, une des menaces au développement du catholicisme en Pologne était aussi le grand nombre de Juifs dans le pays: «Ils sont 300.000 à Varsovie ; c'est un grand danger pour le pays $(10 \%$ de la population $) \gg^{48}$.

Une analyse des documents concernant le voyage des évêques français en Pologne en 1924 conservés dans les archives historiques du diocèse de Paris permet de tirer les conclusions suivantes: alors que pour les évêques polonais le but principal de cette visite était de convenir de la base juridique du ministère pastoral polonais en France, pour les évêques français l'objectif était de connaitre la situation de l'Église en Pologne après les cloisonnements et l'attitude de la société po-

\footnotetext{
${ }^{40}$ Ibid., Sommaire de la Societe des Dames de la Charite de Saint Vincent de Paul.

${ }^{41}$ Ibid., L'Association catholique des ouvres de protection de la jeune fille en Pologne (Varsovie).

${ }^{42}$ Ibid., Statuts de l'Association des ouvrieres polonais et ruthenes en France [Statut Stowarzyszenia robotników polskich i ruskich we Francyi] Paryż 1911.

${ }^{43}$ Ibid., Protecton de 1'Ouvrier Polonais en France. Więcej na temat jej działalności: M.J. Gondek, Jadwiga Zamoyska i jej program pracy społecznej, „Człowiek w Kulturze”, 17 (2005) p. 241-255.

${ }^{44}$ Ibid., Pro memoria.

${ }^{45}$ Ibid., Compte -rendu. But du voyage.

${ }^{46}$ Ibid.

${ }^{47}$ Differance entre «antijudaïsme» et «l'antisémitisme» voir: W. Szczerbiński, Od alienacji do akceptacji. Antysemityzm- antyjudaizm - antyżdowskość - antysyjonizm, „Studia Europea Gnesnensia", 6 (2012) p. 95-108.

${ }^{48}$ AHP., Compte - rendu du visite. Mission en Pologne, Paris, b.d.
} 
lonaise envers la France. Cette visite a été soutenue par le gouvernement français, pour laquelle elle a constitué un moyen de rehausser le prestige de la France sur la scène internationale ${ }^{49}$. La lecture des documents permet non seulement de retracer le déroulement de la visite des invités français, mais aussi de se familiariser avec la description de la vie religieuse en Pologne d'avant-guerre, et avec les activités des associations catholiques. Les évêques français ont été impressionnés par le travail pastoral de l'administrateur apostolique August Hlond ce que le cardinal Dubois a exprimé dans une lettre au Pape Pie XI. On ne peut que supposer que l'avis de ce dignitaire religieux français aurait pu contribuer à la nomination de Monseigneur Hlond deux ans plus tard comme le Primat de Pologne.

Reste à savoir si la visite des évêques français a répondu aux attentes des évêques polonais? Ils ont espéré organiser la pastorale «à la polonaise» (en préservant les coutumes et traditions nationales) des émigrants en France. Bien que lors de la visite, il ait été possible de préparer cet accord («Règlement des aumôniers polonais») et bien que les évêques français aient apprécié et admiré la religiosité des catholiques polonais, ils ont cependant été persuadés que l'amour des Polonais pour la France était tellement grand que la deuxième génération d'émigration polonaise dans l'Hexagone abandonnerait les habitudes et le folklore polonais pour adopter la pastorale française. Les évêques français ont vu les coutumes et traditions polonaises non pas comme inséparables de la foi qu'ils professaient, mais comme une espèce de folklore, une performance accompagnant le culte. $\mathrm{Ce}$ raisonnement est soutenu par le fait qu'après leur retour de Pologne, le 16 décembre 1924, une réunion a eu lieu au siège de l'archevêché de Paris, à laquelle des aumôniers polonais ont été invités. Son objectif était de préparer un statut réglementant les relations mutuelles et les dépendances entre prêtres polonais et français. Pour les autorités françaises, les prêtres polonais devaient avoir le statut de vicaires ou de coopérateurs des curés français. Le clergé polonais avec des espoirs ardents après la visite des évêques français en Pologne espérait sans succès l'indépendance totale du ministère pastoral polonais en France de la juridiction des évêques locaux ${ }^{50}$.

En outre, dans le projet de règlement établi, le cardinal Dubois a complètement ignoré la question de l'organisation de la catéchèse des enfants polonais, la plaçant par défaut sous la juridiction des évêques français ${ }^{51}$. Ce n'est qu'après l'intervention du Primat de Pologne que le droit des missionnaires polonais d'enseigner la religion aux enfants de 7 à 13 ans en polonais a été rédigé. Cependant, à peine deux ans plus tard, en 1926, l'un des participants au voyage en Pologne, Mgr Chaptal a exprimé l'espoir que les enfants des familles polonaises seraient éduqués dans les séminaires français et permettraient de remplacer les missionnaires polonais qui appréciaient l'indépendance vis-à-vis des évêques français ${ }^{52}$.

${ }^{49}$ A. Brzeziński, Z historii francuskiej «dyplomacji kulturalnej» w Polsce w okresie międzywojennym, „Przegląd Zachodni” 1/1995, p. 117-132.

${ }^{50}$ Dzwonkowski, Polska opieka, p. 60.

${ }^{51}$ Ibid., Dubois do Dalbora, Paris 10 I 1926.

${ }^{52}$ E. Chaptal, Une source de vocations sacerdotales dans les familles étrangères en France, „L'étranger catholique en France”, 1 (1926) p. 4-5. 
La signature du document réglementant l'organisation de la pastorale polonaise en France n'a pas clôturé la période de conflits entre prêtres polonais et français sur sa forme. Ils durèrent, avec une intensité plus ou moins grande, jusqu'à la mise en œuvre pratique des recommandations de la constitution «Exsul Familia» du pape Pie XII (1952).

\section{Archives historiques du diocèse de Paris, Louis-Ernest Dubois (sygn. 1D 12,23), Dubois do Piusa XI, Paris, b.d.}

\section{Très Saint-Père}

Votre Sainteté a daigné encourager et bénir le voyage que je me proposais de faire en Pologne sur l'invitation de l'épiscopat Polonais.

De retour à Paris, je me fais un devoir d'écrire à votre Sainteté une brève relation de ce voyage en un pays qui lui est demeuré si cher à tant de titres.

J'avais prié de m'accompagner en Pologne quatre Évêques français particulièrement qualifiés: Monseigneur Chollet, Archevêque de Cambrai ; Monseigneur Julien, Évêque d'Arras dont les diocèses comptent une nombreuse colonie polonaise ; Monseigneur Chaptal, Évêque auxiliaire de Paris pour les étrangers et Monseigneur Baudrillart, Recteur de l'Institut catholique de Paris très informé des choses de Pologne où il a de nombreux amis. Monsieur Symbor Prêtre de la Mission, recteur de l'église polonaise de Paris, devait nous servir de guide et souvent d'interprète.

Le gouvernement français - je suis heureux de le dire - nous facilita toute chose ; il se montra bienveillant et généreux pour assurer le succès de notre Mission. Ordre avait été donné aux représentants de la France de nous recevoir et de se mettre à notre disposition : il en fut ainsi, malgré les modifications politiques survenues en France au moment même de notre départ. Notre Mission a eu plus de relief aux yeux des Polonais si profondément catholiques.

Notre programme comprenait la visite de Cracovie, Varsovie, Posnan, Katowice et comme il convenait un pèlerinage à Czestochowa. Nous restâmes quinze jours en Pologne du 14 au 29 juin.

L'arrivée des Évêques Français fut un événement dans ce pays que de liens si intimes ont toujours uni aux nôtres. C'était pour une population longtemps opprimée une nouvelle occasion de traduire sa reconnaissance envers la France qui avait providentiellement aidé à sa délivrance et surtout son attachement à la fois catholique demeuré durant les longues années de l'oppression, la plus précieuse sauvegarde de la nationalité polonaise et le plus sûr espoir de sa résurrection.

Le gouvernement tint à bien accueillir la Mission qui lui venait de France. Depuis le moment où nous pénétrâmes en Pologne jusqu'à notre départ nous fûmes affectueusement et officiellement ses hôtes : un wagon spécial était mis à notre disposition - nous étions logés à Varsovie au château royal ; à Posnan au château impérial, le Président de la République, le Président du Conseil, les Voywodes, le maire nous recevaient au double titre de dignitaires ecclésiastiques et d'envoyés Français ; la population nous accueillait avec un enthousiasme qui nous émouvait 
profondément et nous faisait mieux sentir l'opportunité de notre présence.

Je dois souligner tout spécialement et avec reconnaissance, le fraternel accueil que nous réservaient les Évêques de Pologne. À Cracovie, le prince-évêque, Monseigneur Sapieha, à Varsovie son Éminence le Cardinal Kakowski, à Posnan son Éminence le Cardinal Dalbor ; à Katowice Monseigneur Hlond, Administrateur apostolique a rivalisé d'attentions bienveillantes dont nous leur demeurons très reconnaissantes. Ils étaient heureux de voir se réaliser un de leurs voeux très chers : attester aux yeux de leur pays l'étroite union de l'épiscopat polonais et de l'épiscopat français pour le plus grand bien de l'Église et de nos deux patries.

Pour nous faire honneur, ils ont réuni autour d'eux les dignitaires officiels et l'élite de leur clergé et des membres des œuvres catholiques : d'où échange de vues non seulement intéressantes mais utiles à cause que nous voulions servir.

Partout aussi des cérémonies religieuses furent organisées qui nous faisaient mieux connaitre l'âme polonaise si pleine de foi, si ardente, si respectueuse du Clergé, si attachée à ses pratiques religieuses: spectacle dont nous fûmes trop édifiés trop émus pour pouvoir jamais l'oublier.

De toutes ces cérémonies, les plus splendides furent ces incomparables processions de la Fête Dieu que Votre Sainteté a vues et présidées Elle-Même, à Varsovie et à Posnan : la participation des pouvoirs publics et du peuple tout entier à ces manifestations religieuses en l'honneur de l'Eucharistie leur donne un éclat triomphal et en font un acte de foi des plus significatifs. Dieu ne saurait ne pas bénir un peuple qui Lui rend de tels hommages.

Nous prîmes contact avec les différentes œuvres catholiques des Diocèses visités. Les autorités ecclésiastiques tenaient à faire défiler devant nous, pour ainsi dire, comme en une rapide revue, les organisations diverses - d'hommes, de jeunes gens, de dames et de jeunes filles - qui groupent pour la prière et l'action même politique au besoin les meilleurs des fidèles.

Votre Sainteté les connait mieux que nous et peut en apprécier avec plus d'autorité et de précision la vie intense et la grande utilité.

Quelques unes sont anciennes déjà, d'autres se fondent sur la poussée des évènements et par nécessité urgente d'apostolat, comme au futur diocèse de Katowice où tant de choses étaient à créer - et se créaient en effet grâce au zèle, à la sage activité de Monseigneur Hlond, Administrateur Apostolique.

Je n'apprends rien à Votre Sainteté, mais il m'est très agréable de témoigner devant Elle - en mon nom et au nom des Prélats qui m'accompagnaient - de cette vitalité religieuse qu'Elle a si souvent constaté Elle-Même au cours de son séjour en Pologne.

Et c'était l'une de nos joies d'entendre rappeler, constamment avec piété filiale, avec fierté, le souvenir des années passées par Votre Sainteté en ce pays qui, au lendemain de la Grande Guerre, fût aux prises avec de si tragiques évènements: le nom de Monseigneur RATTI, Nonce Apostolique, reste pour la Pologne reconnaissante attachée au «miracle de la Vistule», que vos prières et votre indomptable espérance unie à celle du peuple polonais ont obtenu de la protection de la très Sainte Vierge. 
A Czestochowa - comme partout ailleurs, nous trouvions des traces de votre séjour - de tout cour nous avons prié la Madone vénérée pour le chef de l'Église dont elle a si visiblement béni l'apostolat.

Je crois superflu de m'étendre d'avantage sur le détail des cérémonies religieuses, réceptions, visites qui ont marqué notre séjour en Pologne. J'ajoute cependant, qu'à Posnan d'accord avec son éminence le cardinal Dalbor, des dispositions spéciales ont été prises, par les Évêques français intéressés pour assurer la vie religieuse des polonais émigrés en France.

Peut-être sera-t-il plus utile - et j'en sollicite l'autorisation, TRÈS SAINT PÈRE, de soumettre à Votre Sainteté quelques remarques suggérées par circonstances même de notre séjour.

Celle qui vient en premier lieu est toute consolante : c'est que la Pologne - nation Catholique - est aujourd'hui comme hier, profondément attachée à sa foi et à ses pratiques. Du fait même de la reconnaissance politique de la nation polonaise, des facilités plus grandes sont accordées à l'apostolat catholique : et le haut Clergé s'emploie à en profiter plus largement. Votre Sainteté le sait et nous-même fûmes très édifiés sur ce point. Il y a là de grandes espérances pour l'avenir.

Espérance aussi la fécondité des familles polonaise où les enfants très nombreux amènent des recrues à l'Eglise en même temps qu'ils sont une force pour le pays si exposé aux dangers de la guerre. Mais il est nécessaire que s'y maintiennent et s'y propagent avant tout l'école chrétienne, seule sauvegarde des jeunes générations qui s'élèvent si denses et si ardentes.

La population ouvrière - que nous avons surtout rencontré à Katowice et dans les environs - n'est pas encore aussi largement contaminé comme d'autres pays par les doctrines sociales subversives de la Religion et de l'ordre public. Quel danger pour la Pologne - et pour l'Eglise polonaise - si ces ouvriers venaient à subir en majorité les influences néfastes qui, ailleurs, les ont détourné de la foi et des pratiques chrétiennes et en ont fait trop souvent des facteurs de désordre !

Si je me permets ces remarques, TRÈS SAINT PÈRE, c'est qu'elles sont pour moi l'occasion d'une douloureuse comparaison avec ce qui se passe chez nous mais aussi parce que j'y trouve des arguments à faire valoir dans notre chère France en faveur de la religion et pour le salut du Pays.

Ce sera un des résultats de notre Mission nous avons fait pour ainsi dire toucher du doigt l'influence religieuse vivante en un pays ami qui renait et a besoin pour poursuivre sa renaissance du continuel appui de la religion.

Malheureusement les partis avancés - franchement hostiles ou facteurs d'un libéralisme dangereux - quelques noms d'ailleurs qu'on leur donne - ne sont pas sans influence en Pologne et il est à craindre que, de plus en plus, ils n'imposent leur volonté, aidé en cela par les Juifs si nombreux en ce pays. Ce serait un désastre au point de vue religieux et sans doute au point de vue national. On le redoute là-bas - et on nous en parlait en jetant les yeux sur la France.

Tant que nous l'avons pu, nous avons rassuré nos interlocuteurs polonais sur les conséquences que les dernières élections françaises ont opéré dans notre orientation politique, mais nous montrions par notre propre expérience ce qu'il en adviendrait des Institutions religieuses polonaises si les chefs du Pouvoir suivaient 
les principes et les méthodes dont naguère nous avons eu tant à souffrir et dont aujourd'hui encore nous avons tant à craindre. La peur de ce danger encourageait les bonnes volontés.

Dieu veuille épargner à la Pologne les ruines religieuses dont souffre la France, et puisque les deux Nations sont amies et alliées puissent-elles l'être dans les mêmes sentiments de foi chrétienne et de dévouement à la Sainte Eglise.

\section{BIBLIOGRAPHIE}

\section{Source}

Archives historiques du diocèse de Paris

Louis-Ernest Dubois sygn. 1D 12,23

\section{Arrangement}

Boisard Pierre, Monseigneur Chaptal. Evêque d'Isionda (1861-1943), Paris 1945.

Brudzisz Marian, Pierwsze zebranie księży Polskiej Misji Katolickiej we Francji, „Studia Polonijne", 33 (2012) p. 141-154.

Brudzisz Marian, Stan badań nad dziejami Polskiej misji Katolickiej we Francji, w: S. Zych S., B. Walicki, W kręgu badań nad Polonia i duszpasterstwem polonijnym. Istota i metodologia, Lublin-Sokołów Małopolski 2015, p. 321-356.

Brzeziński Andrzej, Z historii francuskiej „,dyplomacji kulturalnej” w Polsce w okresie międzywojennym, „Przegląd Zachodni, 1995, r.51, nr 1, p.117-132.

Chałupczak Henryk, Kołodziej Edward, Zjazdy i konferencje Konsulów Polskich we Francji. Protokoty i referaty 1931-1938, Lublin 2009.

Chaptal Emmanuel, Une source inexplorée de vocations sacerdotales dans les familles étrangères en France, „L'Etranger catholique en France”, (1926) nr 1, p. 4-5.

Clément Jean-Louis, Mgr Chaptal et la Mission diocésaine des étrangers, „Migration et religion en France", 78 (2008) s. 53-63.

Dzwonkowski Roman, Geneza i rola przywódczej grupy społecznej w historii polskiej emigracji zarobkowej we Francji, 1920-1945, „Przegląd Polonijny”, 3 (1979) p. 6982.

Dzwonkowski Roman, Polska opieka religijna we Francji 1909-1939, Poznań-Warszawa 1988.

Garçon Gabriel, Les catholiques polonais en France 1919-1949, Lille 2004.

Marchasson Yves, Monseigneur Beaudrillart et la Pologne (1919-1939), w: Les Contacts religieux franco-polonais du Moyen Age à nos jours. Relations, influences, images d'un pays vu par l'autre, Collectif, Paris 1985.

Ponty Janine, Polonais méconnus. Histoire des travailleurs immigrés en France dans l'entre-deux-guerres, Paris 2005.

Satora Magdalena, Obraz Polski $w$ dziennikach kardynała Alfreda Baudrillarta, Dzieje Najnowsze 2015, t. 2, p. 21-32.

Schor Ralph, L'opinion francaise et les étrangers en France 1919-1939, Paris 1985.

Szymański Józef, „Nie chcemy tego ukrywać” - oczami świadków. Sytuacja duszpasterstwa polonijnego w północnej Francji w 1928 roku, „Archiwa, Biblioteki i Muzea Kościelne", 98 (2012) p. 407-417.

Trąba Mariusz, Relacja biskupa Alfreda Baudrillarta z pobytu na polskim Górnym Ślasku w 1924 roku, ,Zeszyty Chorzowskie”, 8 (2005) p. 62-95. 


\title{
WIZYTA BISKUPÓW FRANCUSKICH W POLSCE W 1924 ROKU W ŚWIETLE MATERIALÓW ZDEPONOWANYCH PRZEZ KARD. DUBOIS (1856-1929) W ARCHIWUM HISTORYCZNYM DIECEZJI PARYSKIEJ
}

\section{Streszczenie}

Na początku lat. 20. XX wieku wychodźstwo polskie we Francji liczyło ponad sto tysięcy ludności. W jego skład wchodzili głównie Polacy z Galicji oraz polscy górnicy z Westfalii.

Pobyt we Francji traktowali oni jako tymczasowy, dlatego też domagali się zapewnienia opieki duszpasterskiej przez polskich księży. Jej organizacja była możliwa jedynie $\mathrm{w}$ porozumieniu $\mathrm{z}$ francuskimi władzami kościelnymi. Celem podpisania stosownej umowy Episkopat Polski zaprosił w 1923 roku francuskich biskupów do złożenia wizyty w Polsce. Miała ona miejsce w czerwcu 1924 roku pod przewodnictwem abp. Paryża. W archiwum diecezji paryskiej znajdują się materiały opisujące jej przebieg, a złożone przez kard. Dubois. Zapoznanie się z ich treścią pozwala lepiej poznać reakcje strony francuskiej w czasie i po zakończeniu podróży do II Rzeczypospolitej.

Słowa kluczowe: Dubois; Dalbor; Chaptal; Baudrillart; Francja, wychodźstwo

\author{
A VISIT OF FRENCH BISHOPS TO POLAND IN 1924 \\ IN THE LIGHT OF MATERIALS DEPOSITED \\ BY CARDINAL DUBOIS (1856-1929) \\ IN THE HISTORICAL ARCHIVES OF THE DIOCESE OF PARIS
}

\section{Summary}

In the early 1920s, the Polish exile in France had a population of over one hundred thousand. It consisted mainly of Poles from Galicia and Polish miners from Westphalia.

They treated their stay in France as temporary, and therefore demanded that Polish priests provided pastoral care. Its installation was only possible in consultation with the French church authorities. In order to sign the relevant agreement, the Polish bishops invited French bishops to visit Poland in 1923. The visit took place in June 1924 under the leadership of Archbishop of Paris. The archives of the Diocese of Paris contain materials describing this event, which were submitted by Cardinal Dubois. By reading their contents, one can learn more about the reactions of the French party during and after the visit to the Second Polish Republic.

Keywords: Dubois; Dalbor; Chaptal; Baudrillart; France; exile 